\title{
A INTERTEXTUALIDADE NO LIVRO DE CIÊNCIAS: ANALISANDO O TEMA SAÚDE E AMBIENTE.
}

\author{
Francine Lopes Pinhão, ${ }^{1}$ Isabel Martins ${ }^{2}$ \\ ${ }^{1}$ Universidade Federal Fluminense, Programa de Pós-graduação Educação em Ciências e Saúde NUTES- \\ UFRJ, pinhaofl@ hotmail.com \\ ${ }^{2}$ Programa de Pós-graduação Educação em Ciências e Saúde NUTES-UFRJ, isabelmartins@ufrj.br
}

\section{Resumo}

Neste trabalho analisamos a constituição do discurso sobre saúde e ambiente numa coleção didática de ciências. Inicialmente justificamos nossa escolha temática explorando a interdependência saúde e ambiente, as diferentes abordagens dadas ao tema e discutindo uma amostra de trabalhos que exploram o tema saúde na escola. $\mathrm{Na}$ sequiência, baseados no referencial teórico metodológico da análise crítica do discurso consideramos o caráter híbrido do livro didático e seu contexto de produção. Em nossas análises priorizamos a categoria intertextualidade, que se complementa por meio da consideração da relação entre aspectos textuais localizados e aspectos das práticas sociais nas quais os textos analisados são produzidos e recebidos. Por fim, consideramos que os movimentos discursivos, bem como a escolha por utilizar um determinado texto fonte e não outro, explicitam escolhas pedagógicas especificas e modos de representar o tema saúde e ambiente. A análise intertextual, onde localizamos as opções por apagamento ou inserção de trechos retirados de textos fonte revela que no processo recontextualização discursiva o direcionamento dado ao texto possui relação direta com as exigências da prática social.

Palavras-chave: Ensino de ciências, livro didático, intertextualidade, saúde e ambiente.

\section{Introdução}

O tema saúde e ambiente tem sido cada vez mais explorado por diferentes áreas do conhecimento. $\mathrm{O}$ interesse surge tanto pela percepção de que a saúde humana, para ser compreendida como um todo, deve ser considerada numa perspectiva ecossistêmica, quanto pelo fato de vivermos um momento de crise ambiental e grandes epidemias. Destes diferentes contextos e abordagens surge uma variedade de formas de conceber a relação saúde e ambiente. Destacamos, em particular, aquelas que estabelecem relações causais entre saúde e ambiente, seja numa perspectiva unicausal ou multicausal. Caminhando no sentido de uma abordagem multicausal, devemos considerar que o ensino de ciências ao tratar de questões relacionadas à saúde e ao ambiente deve enfatizar o caráter invariavelmente interdependente dessas dimensões, a fim de ultrapassar o enfoque unicausal tradicionalmente adotado pelos livros didáticos.

Apesar do debate sobre tais questões já se fazer presente no campo da educação, estudos anteriores sobre o tema saúde no livro didático (CARLINI- CONTRIN e 
ROSEMBERG, 1991; MOHR, 1995) relatam a negligência da dimensão social e ambiental nos textos didáticos. Estes trabalhos são anteriores à formulação dos Parâmetros Curriculares Nacionais (PCN), lançados em 1997, e à prática de avaliação pedagógica dos livros didáticos realizada pelo Plano Nacional do Livro Didático (PNLD), iniciada em 1997. Além disso, a produção acadêmica sobre ensino de ciências, educação em saúde e educação ambiental, tomou maiores proporções tanto em termos de produção acadêmica quanto em termos de inserção na prática, por meio de influência das políticas educacionais.

Atualmente, passados 12 anos da implementação dos PCN e de controle sobre a produção dos livros didáticos via processo de avaliação, cabe nos perguntarmos se encontraríamos o mesmo quadro evidenciado nas pesquisas anteriores. Esta pergunta faz sentido na medida em que, desde então, o mercado editorial tem atendido cada vez mais as exigências do seu maior comprador, o Estado. Desta relação de mercado surge uma nova configuração para os livros didáticos, mas será esta nova configuração mera inclusão superficial das exigências do Estado (mercado consumidor) ou um movimento de mudança discursiva, potencialmente transformadora da realidade educacional?

Em trabalho recente, Freitas e Martins (2008), ao analisarem o tema saúde localizaram a ausência de discussões que considerem diferentes dimensões do conceito de saúde tais como renda, habitação, educação, alimentação adequada, ambiente saudável, recursos sustentáveis, equidade e justiça social.

Os resultados desses trabalhos nos chamaram atenção e decidimos olhar para o livro didático por outro ângulo. Assim, buscamos explorar os textos que contivessem tanto expressões relacionadas com o tema saúde quanto com o tema ambiente, a fim de localizar o modo pelo qual este discurso se constitui no livro didático.

\section{Quadro teórico metodológico}

A partir da Análise crítica do discurso, entendemos que o discurso presente nos livros didáticos de ciências, chamado de científico-escolar, surge numa rede discursiva que traz elementos tanto do discurso científico quanto do didático, bem como elementos de contextualização. Tais características, para Braga e Mortimer (2003), fazem do livro didático de ciências um gênero de discurso particular, que guarda relações com o universo cientifico escolar e cotidiano e surge por meio de hibridização.

A discussão acerca do caráter híbrido dos livros didáticos avança quando se descreve o caráter híbrido do gênero livro didático por meio dos processos de recontextualização, 
no sentido de Bernstein (1996), dos diferentes gêneros e discursos que o compõem, como veremos mais adiante. A referência ao conceito de recontextualização de Bernstein aparece em Chouliaraki e Fairclough (1999), numa discussão acerca das categorias intertexto e interdiscurso, as quais são úteis para a análise dos hibridismos textuais.

O controle da produção dos livros didáticos pelos campos oficiais origina certa homogeneidade das coleções didáticas (Bernstein, 1996). No entanto, ao compreendermos tais discursos para além da relação com o Estado supomos que são recontextualizados, por inserção de outros discursos ou permanência dos anteriores, permitindo que ocorra subversão das recomendações. Tendo em vista estas considerações nos questionamos: Como os discursos sobre o tema saúde-ambiente são recontextualizados nesta coleção didática de ciências? Neste texto priorizamos a análise intertextual, que se dedica a análise da superfície material do texto e se complementa ao relacionarmos as marcas discursivas com o contexto de produção do material analisado.

\section{Princípios de análise}

\section{A escolha da coleção}

Entendendo o livro didático como orientador das práticas docentes, selecionamos a coleção de ciências mais escolhida pelos professores de ciências da rede pública de ensino para o ano de 2008. Segundo dados obtidos junto à Coordenação Geral dos Programas do Livro do Fundo Nacional de Desenvolvimento da Educação (CGPLI/FNDE), a coleção "Projeto Araribá" foi a mais distribuída chegando a 1.032.696 de um total de 10.646.724 livros de ciências distribuído em todo o Brasil. ${ }^{1}$

Para auxiliar nossa busca por textos do livro didático que tratem do temas saúde e ambiente, elaboramos um primeiro conjunto de termos-chave com base na literatura histórica e por meio de trabalho empírico orientado por princípios da análise de conteúdo temática, mais especificamente a leitura flutuante da coleção (MINAYO,2004; BARDIN, 1977). Os termos chave foram organizados em quatro aspectos, que tenta contemplar as diferentes dimensões do tema saúde e ambiente: aspectos sociais econômicos e culturais, aspectos biomédicos, aspectos sanitários e aspectos ecológicos.

\footnotetext{
${ }^{1}$ Todos os dados estatísticos referentes às coleções foram concedidos, via correspondência eletrônica, pela Coordenação Geral dos Programas do Livro - CGPLI/FNDE.
} 
De posse desse conjunto de termos e a fim de selecionar textos que dialogassem com a nossa proposta teórico-metodológica. Contudo, com o objetivo de evitar um possível enviezamento nesta escolha utilizamos no processo de seleção do corpus de pesquisa os parâmetros de exaustividade, homogeneidade e pertinência (Bardin, 1977) para reconhecer todos os textos da coleção que tratassem do tema.

Para chegarmos ao conjunto de textos a ser analisado levamos em consideração três parâmetros: (1) a presença de descritores vinculados aos quatro aspectos propostos anteriormente; (2) a explicitação das suas fontes de referência pelo autor e; (3) a diversidade de gêneros discursivos dos textos que serviram de fonte para a elaboração

\begin{tabular}{|c|c|c|c|}
\hline Série & $\begin{array}{c}\text { Título do } \\
\text { Texto do LD }\end{array}$ & $\begin{array}{c}\text { Título do } \\
\text { Texto fonte }\end{array}$ & $\begin{array}{c}\text { Gênero discursivo do } \\
\text { texto fonte }\end{array}$ \\
\hline $5^{\mathrm{a}}$. série & $\begin{array}{l}\text { Como reduzir a poluição do } \\
\text { solo? }\end{array}$ & Receita de solo & Divulgação científica \\
\hline $5^{\mathrm{a}}$. série & A contaminação da água & Poluição da água & Gênero didático \\
\hline $5^{\mathrm{a}}$. série & $\begin{array}{l}\text { Manguezais: exploração e } \\
\text { preservação }\end{array}$ & $\begin{array}{l}\text { "Criança- } \\
\text { caranguejo" vive da } \\
\text { lama no Rio }\end{array}$ & Reportagem jornalística \\
\hline
\end{tabular}

do texto didático. Tal seleção de textos nos permite verificar as alterações realizadas na superfície material do texto, bem como discutir a natureza dessas escolhas discursivas no âmbito macrossocial. Abaixo apresentamos os textos analisados:

\begin{tabular}{|c|c|c|c|}
\hline & & $\begin{array}{l}\text { Manifesto } \\
\text { Manguebeat }\end{array}$ & Manifesto \\
\hline $6^{\mathrm{a}}$. série & Lagoa Azul está doente & $\begin{array}{l}\text { Lagoa azul está } \\
\text { doente }\end{array}$ & Questão de prova \\
\hline \multirow[t]{3}{*}{$6^{\mathrm{a}}$. série } & \multirow{3}{*}{ Animais de estimação } & $\begin{array}{l}\text { O programa saúde } \\
\text { do animal }\end{array}$ & Texto de website \\
\hline & & O que é a raiva & Texto de website \\
\hline & & Sem título & \\
\hline $8^{\mathrm{a}}$. série & A tintura de tecidos & Corantes têxteis & Artigo científico \\
\hline
\end{tabular}

Tabela 1: Corpus da pesquisa

\section{Intertextualidade}

Um texto fonte, ao ser usado para compor o texto do livro didático, pode ser representado de maneira direta ou indireta. A primeira é reconhecida pelo uso de citações e a segunda por meio de paráfrases. No processo de representação indireta podem ocorrer reelaborações discursivas que envolvem a inclusão e/ou o apagamento de informações, além de modificações que dizem respeito ao tempo verbal, ao uso de 
sinônimos, entre outras que podem emergir no momento de análise. Estas marcas textuais auxiliam na identificação e interpretação dos movimentos discursivos usados no processo de didatização. Ao selecionarmos o corpus da pesquisa, um de nossos critérios se relacionava ao gênero discursivo do texto fonte usado para compor o texto didático.

Tomando como pressuposto o fato de que os gêneros discursivos são produtos de práticas sociais específicas (FAIRCLOUGH, 2001), podemos supor a existência de uma relação direta entre as escolhas feitas pelos autores e seus contextos de produção discursiva. Nesse sentido, propomos que durante o processo de recontextualização as escolhas feitas pelos autores do livro didático são principalmente pautadas no apagamento das características discursivas típicas dos gêneros discursivos de cada texto fonte e na inclusão daquelas identificadas, ou potencialmente úteis, para o gênero didático. Abaixo apresentamos um exemplo do quadro analítico usado para identificarmos tais realizações discursivas e um resumo das principais operações realizadas em cada texto.

\section{Texto1 - Como reduzir a poluição do solo?}

O texto didático "Como reduzir a poluição do solo?" é construído com base em um texto de divulgação científica publicado na revista Ciência Hoje das Crianças ${ }^{2}$. De acordo com Martins, Nascimento e Bueno (2004), o fato dos textos de divulgação científica não serem elaborados originalmente para uso no espaço escolar leva a necessidade de haver adaptações do texto para uso em sala de aula ou para compor um livro didático.

O processo de reelaboração discursiva deste texto foi realizado, principalmente, por eliminação de informações. Como o texto original possui 4 quatro páginas e o espaço reservado à seção onde o texto foi inserido é sempre de uma página e meia, podemos supor que uma das motivações para tantas eliminações tenha sido esta própria característica do projeto editorial. No entanto, a opção por um trecho e não outro traz conseqüências para a apresentação final do assunto. No quadro 1 apresentamos um exemplo que mostra a natureza das informações que foram escolhidas para compor o texto didático e das que foram eliminadas.

\footnotetext{
${ }^{2}$ Receita de Solo. Ciência Hoje das Crianças. No. 105, Ago. 2000.
} 
Quadro 1: Exemplo extraído do texto didático intitulado "Como reduzir a poluição do solo?”

\begin{tabular}{|c|c|c|}
\hline Texto livro didático & Texto fonte & Operações discursivas \\
\hline $\begin{array}{l}\text { Outra técnica utilizada é a } \\
\text { biorremediação. Trata-se de } \\
\text { usar organismos vivos para } \\
\text { atuarem como "faxineiros" do } \\
\text { solo! } \\
\text { Algumas bactérias, por } \\
\text { exemplo, são utilizdas para } \\
\text { limpar terrenos contaminados } \\
\text { por óleo. }\end{array}$ & 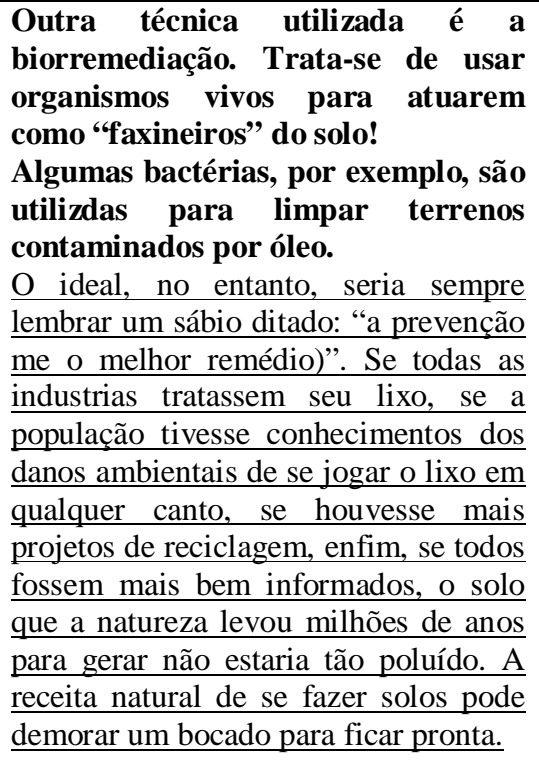 & $\begin{array}{l}\text { Representação direta } \\
\text { Eliminação informacional }\end{array}$ \\
\hline
\end{tabular}

O texto didático foi construído por meio da eliminação de: (i) referências às diferentes esferas sociais envolvidas no problema da poluição (as indústrias, a população e o governo); (ii) informações sobre as diversas fontes de contaminação do solo e do lençol freático; (iii) ênfase à escala temporal do processo de constituição dos diferentes tipos de solos e; (iv) do nome da empresa que produziu o texto de divulgação científica, a Petrobrás. Já os trechos escolhidos para compor o texto didático foram aqueles com ênfase na apresentação das conseqüências de se manter lixões e do processo de contaminação e descontaminação do lençol freático.

Além disso, foram incluídas perguntas ao final do texto, onde localizamos a existência de termos como "reutilizar" e "redução de consumo". Estes conceitos não são, no entanto, problematizados e aparecem apenas em perguntas que solicitam do aluno a confecção de uma lista de produtos recicláveis e reutilizáveis.

Finalmente, o título do texto didático, a saber, "Como reduzir a poluição do solo?", apresenta como pressuposição a existência da poluição, tomando o tema como dado. Percebemos que tais opções tornaram o texto didático menos problematizador que o texto de divulgação científica. 


\section{Texto 2 - A contaminação da água}

O texto fonte usado para compor o texto didático "A contaminação da água" pertence ao gênero didático, pois faz parte de uma coleção de ensino a distância do Telecurso $1^{\circ}$. Grau. ${ }^{3}$. Apesar do texto fonte também ser voltado para o ensino da disciplina escolar ciências, a principal diferença entre este e o texto do livro didático reside no fato de que um livro didático é concebido para uso em sala de aula, pressupondo orientações de um professor, enquanto uma apostila para ensino a distância é um material para estudo orientado, mas se dá de maneira mais autônoma e fora do ambiente escolar. Tendo em vista estas características, notamos que a recontextualização do texto fonte se deu por meio da eliminação de perguntas que orientavam a leitura e repetições de informações que tornavam o texto mais extenso.

O texto fonte, composto por 5 páginas, foi usado para a composição de um texto didático de uma página, mais curto e objetivo. Os trechos retirados do texto fonte foram inseridos no texto didático, de modo geral, por meio de representação direta e reordenação lexical. Eles permitiram uma discussão em torno de dados técnicos encomendados por "autoridades" da região. O termo "autoridades" não revela se estes eram políticos, delegados ou líderes comunitários. Assim, ocorre um pagamento dos diferentes sujeitos possivelmente envolvidos com a questão e resta uma pergunta, quem possui autoridade para convocar técnicos e resolver os problemas da região? Quais foram os responsáveis pela solução do problema?

\section{Texto 3 - Manguezais: exploração e preservação}

Os autores do Livro didático indicam duas referências usadas para compor o texto "Manguezais: exploração e preservação". Estas são uma reportagem jornalística e um manifesto. A reportagem ${ }^{4}$ explora o a questão do trabalho infantil no manguezal de Guapimirim, Rio de Janeiro. O manifesto intitulado "Caranguejos com Cérebro" surge do movimento cultural Manguebeat e visa à valorização da população que vive nos e dos manguezais.

Por meio de pressuposição os autores do texto didático atribuem, a priori, uma dada importância ao manguezal em função do quantitativo de espécies e das características fisionômicas da região. Em outras palavras, atribuem valor ao

\footnotetext{
${ }^{3}$ A contaminação da água. In:Jornal do Televurso $1^{\circ}$ - Ciências São Paulo: Editora Globo, 1990.

${ }^{4}$ Extraída do Jornal Folha de São Paulo, publicada em 06 de junho de 1999.
} 
ecossistema apenas por meio de informações científicas sem fazer menção à importância da região para a população humana local.

Percebemos que, de modo geral, os autores eliminaram do texto jornalístico características típicas desse gênero, como por exemplo, termos com apelo sensacionalista; identificação dos sujeitos envolvidos no problema apresentado e informações sobre a administração da região.

Já em outro trecho do texto, os autores do livro didático fazem uso do manifesto "Caranguejos com Cérebro" elaborado pelo movimento cultural Manguebeat, por meio de representação discursiva direta. É feito uso de um trecho que fala especificamente sobre como o processo de aterramento da cidade. No entanto, a história que antecede este processo e o tema do resgate da dignidade do povo por meio do movimento cultural, presentes no texto do manifesto, são eliminados pelos autores do livro didático. De modo geral, percebemos que o foco do texto didático recaiu sobre a descrição e não sobre a problematização.

\section{Texto 4 - Lagoa Azul está doente}

O texto usado como fonte para a elaboração do texto didático "Lagoa Azul está doente" foi extraído da prova do Exame Nacional do Ensino Médio (ENEM). De modo geral não houve modificação do texto original e o intertexto foi realizado por meio de representação direta. Os principais movimentos de reelaboração discursiva foram a eliminação das opções de respostas presentes na questão do ENEM, que é um exame de múltipla escolha, e a inclusão de perguntas do tipo discursiva, imagem e glossário.

Essas escolhas caracterizam uma finalidade pedagógica diferente daquela proposta pela questão do ENEM, pois as inclusões feitas no texto para compor o livro didático suscitam maior problematização do tema do que propõe a questão do ENEM, que se limita a solicitar uma única resposta do estudante.

\section{Texto 5 - Animais de estimação}

A produção do texto didático "Animais de Estimação" se deu a partir de três fontes de referência. Dentre elas, conseguimos acesso a duas, pois são textos divulgados em websites. Ambos os textos são de caráter informativo. Um deles foi extraído da página de apresentação do website "Saúde do Animal", da Prefeitura de São Paulo e o outro foi retirado do website do Instituto Pasteur de São Paulo, especificamente da página dedicada a informações sobre a raiva. 
O texto de website que trata do programa "Saúde do Animal" foi introduzido, de maneira geral por representação direta. No entanto houve substituição de algumas palavras como, por exemplo, o termo eutanásia foi substituído por expressão que continha o adjetivo "abatidos" e o termo objetivo foi substituído por missão. O mesmo ocorre quando os autores fazem uso do website do Instituto Pasteur, pois o uso do texto fonte se apresenta principalmente por representação direta.

Ao examinarmos os trechos que não foram selecionados pelos autores do livro didático percebemos que alguns possíveis intertextos ficaram ausentes. Foi realizada, por exemplo, a eliminação de informações sobre a maior incidência da raiva em países subdesenvolvidos ou em desenvolvimento. Além das ausências, representações diretas e substituições lexicais, o processo de recontextualização também se deu a partir da inclusão de informações, o que, neste caso, permitiu atribuir valor moral ao problema. Também foram incluídas imagens de animais sadios e animais abandonados, tabelas e gráficos, além perguntas cujas respostas demandam a leitura desses últimos.

Consideramos que por meio da recontextualização dos textos para composição deste texto didático a ênfase do assunto tratado fica centrada no papel do proprietário do animal, de modo que discussões mais amplas sobre a responsabilidade dos demais setores da sociedade acabam sendo perdidas.

\section{Texto 6 - A tintura de tecidos}

O texto didático "A tintura de tecidos" foi elaborado com base em um texto cientifico, que continha uma serie de informações que exigiam alto nível de conhecimento da disciplina química ${ }^{5}$. Nesse sentido, percebemos que as principais reelaborações discursivas foram centradas na eliminação de informações que exigem do leitor um conhecimento especializado e mais aprofundado dos princípios da química. Alem dos termos científicos, todas as imagens de compostos orgânicos foram eliminadas.

Os trechos escolhidos para compor o texto didático são descritivos e, em geral, foram incluídos por meio de representação direta. Além de trechos oriundos do texto fonte, o texto didático foi construído por meio de inclusão de informações como, por exemplo, a ação danosa dos corantes em animais e plantas. Esta forma retira a centralidade da discussão na saúde do ser humano e amplia o sentido dado ao aspecto da

\footnotetext{
${ }^{5}$ GUARATINI, Cláudia C. I. and ZANONI, Maria Valnice B.. Corantes têxteis. Quím. Nova [online]. Vol.23, n.1, 2000.
} 
poluição e suas consequências. Diferente do texto original, o texto didático não apresenta formas de solucionar o problema, mas inclui perguntas e propostas de trabalho para os estudantes que solicitam a proposição de soluções.

Tendo em vista a natureza didática do texto do livro e a natureza informativa do texto acadêmico, que se propunha a realizar uma revisão sobre o tema, notamos que a quantidade de informações foi reduzida e simplificada. Além disso, nem todas as discussões existentes no texto acadêmico foram incluídas na composição do texto didático. Apesar disso, a inclusão de perguntas ao final do texto do LD representou a inclusão de potenciais fontes para a ampliação da discussão sobre poluição. Sendo assim, mesmo que o texto do LD não contemplasse a variedade de pontos do texto original, estes poderiam vir à tona por meio das perguntas inseridas ao final do texto.

\section{Buscando relação com a prática social}

Nossas análises se completam por meio da elaboração da relação entre aspectos textuais e aspectos de práticas sociais nas quais os textos analisados - livro didático-, são produzidos e recebidos. Por meio de nossas análises chegamos à conclusão de que tais movimentos discursivos bem como, a escolha por utilizar um determinado texto fonte e não outro, explicitam escolhas pedagógicas especificas e modos de representar o tema saúde e ambiente.

A análise intertextual, onde localizamos as opções por apagamento ou inserção de trechos retirados de textos fonte, revela que no processo recontextualização discursiva o direcionamento dado ao texto possui relação direta com as exigências da prática social. Observamos que, em geral, os apagamentos de algumas vozes e discursos presentes no texto fonte diziam respeito à desconstrução da estrutura genérica original, bem como a finalidade de adequação do texto ao gênero livro didático. Podemos exemplificar nossa afirmativa ao resgatarmos os textos 3 e 6 . O primeiro se caracteriza pelo apagamento das identidades dos sujeitos envolvidos na problemática apresentada e dos termos sensacionalistas, os quais são características típicas dos textos jornalísticos, principalmente, aqueles voltados para a denúncia. Já o segundo texto é marcado pelo apagamento de conteúdos da química orgânica e de termos técnicos típicos de um artigo científico, onde o objetivo é traçar diálogo com uma comunidade de pares que compartilha de um mesmo conhecimento.

Os processos de reordenação informacional dos textos foram realizados de acordo com as exigências das subseções para as quais os textos estavam sendo 
construídos. No caso específico desta pesquisa os textos que compunham o corpus pertenciam a duas subseções distintas, intituladas pelos autores do livro didático como: "Por uma nova atitude" e "Explore". Em ambos os casos houve, no processo de recontextualização, necessidade de subdivisão dos textos fonte para que fosse criada uma estrutura lógica que obedeceu à seguinte seqüência: apresentação do problema; breve analise do problema e proposta de soluções ou pedido de soluções para o leitor.

Identificamos a existência dessas seções, bem como a opção dos autores por inserirem, preferencialmente, nesses espaços da coleção temas sócio científicos, como sendo uma apropriação do discurso veiculado pelos contextos de exigências vinculados à prática social em questão exercido, especialmente, pelo PNLD e pelo PNC Ciências. Esses materiais são classificados, de acordo com Bernstein (1996), como campos recontextualizadores oficiais. Segundo o mesmo autor, quanto maior a ação do Estado no controle destes textos, mais limitadas são as possibilidades de recontextualização do discurso pedagógico. Isso provavelmente acaba por originar certa homogeneidade nestes materiais.

Podemos interpretar as seções "Por uma nova atitude" e "Explore" como uma tendência de mudança discursiva. De acordo com Fairclough (2001) tem sido comum a diversos discursos da contemporaneidade a tendência de comodificação discursiva. O discurso educacional dirigido ao desenvolvimento de atitudes, habilidade e comportamento se aproxima daquele preconizado pela cultura da eficiência empresarial, ao tomar de empréstimo o seu vocabulário. Para além de palavras como: competência e habilidade, todo um ideário empresarial passa a colonizar a educação e nesse sentido o ensino torna-se comodificado. (FARICLOUGH, 2001). Acreditamos que práticas desenvolvidas com tal objetivo podem levara a uma ação pedagógica que vise apenas à transmissão de informações e a mudança de comportamento. Assim, voltam se principalmente para a crença na possibilidade de uma nova conformação social por meio de novos comportamentos, adquiridos por meio do conhecimento escolarizado.

É possível problematizar esta perspectiva, ao interpretarmos a opção dos autores como uma aproximação a uma educação que vise o desenvolvimento de novas atitudes por meio de alfabetização científica, onde a introdução dos estudantes nesse campo de conhecimento a poderá torná-lo apto a compreender o mundo natural, historicamente elaborado segundo padrões da ciência moderna e, quem sabe, transformá-lo (CHASSOT, 2003). No entanto, através de nossas análises discursivas podemos 
concluir que a presença do discurso tecnocrático (texto 1 e texto 2), do discurso sóciohistórico descolado de uma visão política (texto 3), do discurso preventivo em saúde (texto 6) e dos demais discursos apresentados na seção anterior, não nos permite relacionar a proposta das subseções analisadas, qual sejam, o desenvolvimento de atitudes e a proposta de soluções para problemas, a uma abordagem de tomada de decisão democrática. Com base em Santos e Mortimer (2001) avaliamos ser mais pertinente classificar os textos como vinculados, de um lado a uma abordagem tecnocrática, onde a tomada de decisão se baseia nos especialistas da área, e do outro a uma decisionista, onde cidadãos também são consultados para tomada de decisão, no tratamento de questões sócio ambientais.

\section{Conclusão}

Finalmente, por meio das evidencias discursivas encontradas, pode-se dizer que a abordagem dada ao tema saúde-ambiente não é elaborada única e exclusivamente por meio de causas biológicas. No entanto, a mobilização de termos vinculados a aspectos sociais e/ou econômicos não proporcionou mudança de paradigma, mantendo a unicausalidade. Cabe aqui nos questionarmos sobre a natureza das mudanças discursivas operadas nesse texto, já que, apesar da inclusão de termos vinculados as diferentes dimensões da saúde e ambiente o tema não é abordado sob uma perspectiva multidimensional. Tal achado nos leva a concluir que nesta coleção, a subordinação dos temas aos conteúdos curriculares tradicionais de cada série, bem como a permanência de um tratamento unicausal ao tema indica a permanência discursiva e superficial relação com recomendações oficiais.

\section{AGRADECIMENTOS}

Trabalho realizado com apoio da CAPES/DS e do CNPq (Edital Ciências Humanas 2006)

\section{REFERÊNCIAS}

BARDIN, L. Análise de Conteúdo. Lisboa, Edições 70, 1977.

BERNSTEIN, B. A estruturação do discurso pedagógico: classe, código, controle. Petrópolis: Vozes, 1996.

BRAGA, S. M. A. e MORTIMER, E.F. Os gêneros de discurso do texto de biologia dos livros didáticos de ciências. Revista brasileira de Pesquisa em Educação em Ciências, v.3, n.3, set/dez. 2003. 
CARLINI-COTRIM, B. \& ROSEMBERG, F. Os livros didáticos e o ensino para a saúde: o caso das drogas psicotrópicas. Rev. Saúde pública. 1991.

CHASSOT, A. Alfabetização científica: uma possibilidade para a inclusão social. Revista Brasileira de Educação. n. 22, Jan/Fev/Mar/Abr 2003.

CHOULIARAKI, L.; FAIRCLOUGH, N. Discourse in late modernity: rethinking critical discourse analysis. Edinburgh: Edinburgh University Press, 1999.

FAIRCLOUGH, N. Discurso e mudança social. Brasília: Universidade de Brasília, 2001.

FREITAS, E. O.; MARTINS, I. Transversalidade, formação para a cidadania e Promoção da saúde no livro didático de ciências. Ensino, Saúde e Ambiente, v.1, n.1, p 12-28, ago.2008.

MARTINS, I. ; Nascimento, TG; ABREU, T. B.. Clonagem na sala de aula: um exemplo de uso didático de um texto de divulgação científica. Investigações em Ensino de Ciências, v. 09, n. 01, 2004.

MINAYO, M.C.S. O desafio do conhecimento: pesquisa qualitativa em saúde. 8. ed São Paulo: Hucitec, 2004.

MOHR, A. A saúde na escola: análise de livros didáticos de $1^{\mathrm{a}}$ a $4^{\mathrm{a}}$ séries. Cadernos de Pesquisa, n.94, p.50-57, 1995.

SANTOS, W.L. P.; MORTIMER, E. F. Tomada de decisão para ação social responsável no ensino de Ciências. Ciência \& Educação, v. 7(1), 2001. 